\title{
Breast papillary lesions diagnosed and treated using ultrasound-guided vacuum- assisted excision
}

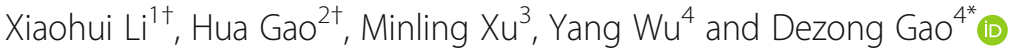

\begin{abstract}
Background: The management of papillary lesions of the breast remains controversial, and thus, we assessed the value of vacuum-assisted excision (VAE)-guided ultrasound in the diagnosis and treatment of breast papillary lesions.

Methods: We retrospectively reviewed the data of 108 patients with papillary lesions diagnosed using VAE between August 2014 and January 2019. Cases without postoperative breast imaging in the follow-up were excluded, and 85 cases were eligible for the study. The follow-up period ranged from 6 to 53 months, with 38 months on average. All the papillary lesions were located away from the skin or nipple with a size less than or equal to $30 \mathrm{~mm}$, and the lesions categorized as C2-4b were completely excised using VAE. All VAEs were performed using an 8-gauge vacuum-assisted biopsy needle under the guidance of ultrasound using a $10 \mathrm{MHz}$ linear probe.

Results: Most patients with breast papillary lesions were asymptomatic (56.5\%), and when the size of the breast papillary lesion was more than $20 \mathrm{~mm}$ on ultrasound imaging, atypical hyperplasia may have been concomitant. Breast lesions might have been pathologically diagnosed as papilloma after biopsy when they were categorized as BI-RADS 4a on ultrasound images. The rate of underestimation was $7.7 \%$ in papillary lesions diagnosed with VAE, and the recurrence rate of papilloma after VAE was low.

Conclusions: Breast papilloma was a common lesion on ultrasonographic screening, and VAE was applicable for completely excising small papillomas, even papillomas with atypical hyperplasia, to obtain an accurate diagnosis with a low rate of underestimation and recurrence. We believe that papilloma diagnosed by VAE might not require immediate excision, and imaging follow-up may be safe for at least 3 years.
\end{abstract}

Keywords: Papillary lesions, Breast, VAE, Treatment

\footnotetext{
* Correspondence: gaohill100@yeah.net

${ }^{+}$Xiaohui Li and Hua Gao are the co-first authors.

${ }^{4}$ Department of Breast Surgery, The Second Hospital, Shandong University

Cheeloo College of Medicine, No. 247, Beiyuandajie Street, Jinan 250033,

China

Full list of author information is available at the end of the article
}

(c) The Author(s). 2020 Open Access This article is licensed under a Creative Commons Attribution 4.0 International License, which permits use, sharing, adaptation, distribution and reproduction in any medium or format, as long as you give appropriate credit to the original author(s) and the source, provide a link to the Creative Commons licence, and indicate if changes were made. The images or other third party material in this article are included in the article's Creative Commons licence, unless indicated otherwise in a credit line to the material. If material is not included in the article's Creative Commons licence and your intended use is not permitted by statutory regulation or exceeds the permitted use, you will need to obtain permission directly from the copyright holder. To view a copy of this licence, visit http://creativecommons.org/licenses/by/4.0/. The Creative Commons Public Domain Dedication waiver (http://creativecommons.org/publicdomain/zero/1.0/) applies to the data made available in this article, unless otherwise stated in a credit line to the data. 


\section{Background}

With the development of screening techniques and imaging diagnostics, more breast papillary lesions are detected in the preclinical stage. Papillary lesions are common in breast biopsies, and the incidence has increased steadily over the past decade [1]. The papillary lesions include benign papilloma, atypical hyperplasia and papillary carcinoma; therefore, it is important to determine whether a lesion is benign or malignant. Core-needle biopsy (CNB) has become widely used in diagnosing breast disease. Some studies have shown that intraductal papilloma (IDP) without atypia diagnosed by core-needle biopsy has a low rate of canceration but that a papilloma with atypia has an increased risk of developing malignancy $[2,3]$.

Compared with open surgical biopsy, examination by $\mathrm{CNB}$ is more easily accepted by patients. However, because of the small portion of lesions with $\mathrm{CNB}$, it is sometimes difficult for pathologists to differentiate between benign and malignant disease [4]. Furthermore, the histological distinction between benign hyperplasia and atypical hyperplasia (AHP) can be subtle, and papillary lesions on $\mathrm{CNB}$ are often diagnostically challenging for pathologists. Thus, an adequate number of specimens is essential for a correct diagnosis.

Vacuum-assisted core biopsy (VACB), as a minimally invasive diagnostic method, could provide sufficient samples from a single insertion compared to a traditional core needle biopsy [5]. VACB eliminated the disadvantages of $\mathrm{CNB}$ to a large extent and was used to diagnose breast focal lesions, with $98-100 \%$ diagnostic accuracy for breast lumps [5]. VACB is primarily used as a diagnostic method; in some cases, especially with smaller lesions, the method can be used therapeutically (vacuum-assisted excision VAE). It was reported that $92 \%$ of benign breast lesions with diameters less than $15 \mathrm{~mm}$ could be totally removed with VAE [6]. Furthermore, VAE may be used for further diagnoses of benign IDP without atypia on CNB [7].

Considering these advantages of VAE and the dilemmas in dealing with breast papillary lesions, in the present study, we assessed the value of ultrasoundguided VAE in the diagnosis and treatment of breast papillary lesions without initial CNB.

\section{Material and methods}

We retrospectively reviewed the data of 108 patients with papillary lesions diagnosed using VAE between $\mathrm{Au}$ gust 2014 and January 2019 at the Department of Breast Surgery, the Second Hospital of Shandong University Cheeloo College of Medicine, China. All breast lesions were categorized as BI-RADS 2 to $4 \mathrm{c}$ on ultrasound images or mammograms. We selected cases of lesions that were located away from the skin or nipple with a size less than or equal to $30 \mathrm{~mm}$ (peripheral lesions), and lesions that were not categorized as $4 \mathrm{c}$ on images were completely excised using VAE. All women who were enrolled in the study underwent an ultrasonographic examination, and those over 40 years of age also underwent mammography. We excluded 5 patients diagnosed with malignant papillary lesions on VAE, and patients without postoperative breast imaging in the follow-up were also excluded; consequently, 85 patients were eligible for inclusion in the study. Of 85 patients, 11 had bilateral lesions, and 96 VAEs were completed. All VAEs were performed using an 8-gauge vacuum-assisted biopsy needle (Mammotome; Devicor Medical Products, Cincinnati, USA) under ultrasound guidance (LOGIQ 5) using a $10 \mathrm{MHz}$ linear probe.

The average patient age was 43.6 years ( $26-82$ years). Of 85 patients, 48 were asymptomatic (56.5\%) with only an abnormal imaging check-up, 22 presented with a discharge, 10 presented with a lump, and only 5 patients complained of breast pain. All patients presented with ultrasonographic nodules, and the size of the biopsied lesions ranged from 5 $\mathrm{mm}$ to $30 \mathrm{~mm}$ (mean: $12 \mathrm{~mm}$ ). IDP in the bilateral breast and multifocal papilloma in the unilateral breast were unusual. BI-RADS 4a was the most common category in the prebiopsy image (54.2\%). The clinical and morphological features of the biopsied breast lesions are shown in Table 1.

Benign IDPs included benign proliferative lesions, such as usual ductal hyperplasia or adenosis, fibrocystic changes, and columnar cell changes. IDP with AHP included lobular intraepithelial neoplasia and ductal atypical hyperplasia. Malignant lesions included papillary cancer with or without ducal carcinoma in situ (DCIS). Two pathologists with extensive expertise in breast lesions reviewed all cases. The patients were followed up with clinical and ultrasound examinations for 3 and 6 months after the operation and then with ultrasound and mammography (at ages greater than 40 years) annually. The follow-up period ranged from 6 to 53 months, with 38 months on average. This study was approved by the Ethics Committee of the Second Hospital of Shandong University, and informed consent was waived.

\section{Statistical analysis}

Statistical analysis was performed using SPSS version 21.0 software (IBM Corp, Armonk, USA). A t-test was used to compare the mean diameters between IDP lesions and IDP with APH lesions. The chi-square test was used to compare the ultrasound identification efficacy between patients with nipple discharge and patients without nipple discharge. Statistical significance was defined as a $p$-value $<0.05$. All reported $p$-values were two-sided.

\section{Results}

Of the 96 VAEs, the initial diagnoses were 81 IDPs and 15 IDPs with AHP. The mean lesion diameter in IDPs with AHP was significantly longer than that in IDPs 
Table 1 Baseline characteristics $(n=85)$

\begin{tabular}{|c|c|}
\hline Characteristic & No. (\%) \\
\hline $\operatorname{Age}^{a}(y r)$ & $43.6(26-82)$ \\
\hline \multicolumn{2}{|l|}{ Cause of detection } \\
\hline Medical checkup without symptom & $48(56.5)$ \\
\hline Nipple discharge & $22(25.9)$ \\
\hline Palpable mass & $10(11.8)$ \\
\hline Breast pain & $5(5.8)$ \\
\hline \multicolumn{2}{|l|}{ Side } \\
\hline Right & $38(44.7)$ \\
\hline Left & $36(42.4)$ \\
\hline Both side & $11(12.9)$ \\
\hline \multicolumn{2}{|l|}{ IDP with other benign lesions } \\
\hline Yes & $6(7.1)$ \\
\hline No & $79(92.9)$ \\
\hline \multicolumn{2}{|l|}{ Multifocality } \\
\hline Yes & $10(11.8)$ \\
\hline No & $75(88.2)$ \\
\hline \multicolumn{2}{|l|}{ BI-RADS category } \\
\hline $\mathrm{C} 2$ & $9(10.6)$ \\
\hline $\mathrm{C} 3$ & $20(23.5)$ \\
\hline C4a & $46(54.2)$ \\
\hline$c 4 b$ & $7(8.2)$ \\
\hline $\mathrm{C} 4 \mathrm{C}$ & $3(3.5)$ \\
\hline \multicolumn{2}{|c|}{ Ultrasonographic identification of intraductal lesion } \\
\hline Yes & $27(31.8)$ \\
\hline No & $58(68.2)$ \\
\hline Size $(m m)^{a}$ & $12(5-30)$ \\
\hline No of samples biopsied ${ }^{a}$ & $8(5-28)$ \\
\hline \multicolumn{2}{|l|}{ IDP with $A H P^{b}$} \\
\hline Yes & 15 (15.6) \\
\hline No & $81(84.4)$ \\
\hline
\end{tabular}

BI-RADS Breast imaging reporting and data system, VAE

Vacuum-assisted excision

${ }^{\mathrm{a}}$ Mean (range). ${ }^{\mathrm{b}} 96 \mathrm{VAE}$ including 11 bilateral papillary lesions

(mean $21 \mathrm{~mm}$ in IDP with AHP and $13 \mathrm{~mm}$ in IDP, Table 2). Except for lesion diameter, IDP with AHP had no special characteristics compared with IDP. The rate of ultrasonographic identification of IDP in patients with nipple discharge was higher than that in patients without nipple discharge (Table 3). To verify the diagnostic

Table 2 Diameters of IDP lesions and IDP with APH lesions

\begin{tabular}{llll}
\hline Lesions & $\begin{array}{l}\text { Diameter }(\mathrm{mm}) \\
\text { mean (range) }\end{array}$ & $\mathbf{s}$ & $\boldsymbol{P}$ \\
\hline IDP & $13(5-30)$ & 8.7 & \\
IDP with APH & $21(12-28)$ & 12.4 & $<0.01$ \\
\hline
\end{tabular}

Table 3 US identification of IDP in 96 VAEs with nipple discharge or not

\begin{tabular}{llllll}
\hline \multirow{2}{*}{$\begin{array}{l}\text { US } \\
\text { identification }\end{array}$} & \multicolumn{2}{l}{ Nipple discharge } & $\mathbf{X}^{\mathbf{2}}$ & $\boldsymbol{P}$ \\
\cline { 2 - 3 } & Yes & No & & \\
\hline Yes & 14 & 17 & & \\
No & 8 & 57 & 12.83 & $<0.01$ \\
\hline US Ultra-sonogram & & & &
\end{tabular}

accuracy of VAE, 26 patients (10 patients with BI-RADS category $4 \mathrm{~b}$ and $4 \mathrm{c}$ on images) underwent open extended excision after VAE (including 16 IDPs and 10 IDPs with AHP). The results of all pathological examinations were the same as the initial diagnosis except for 2 cases. One was diagnosed as IDP with AHP initially diagnosed as IDP, and the other was diagnosed as intraductal papillary carcinoma initially diagnosed as IDP with sclerosing adenosis. The BI-RADS category was 4a on US image in the upgraded malignant patient, but her contralateral mass was invasive ductal carcinoma. However, the histopathological examinations were all benign in 10 patients with BI-RADS category $4 \mathrm{~b}$ and $4 \mathrm{c}$ on images (IDP in 6 patients and IDP with APH in 4 patients). Open excision revealed an underestimation of $2 / 26$ (7.7\%). All 26 patients who underwent open surgery were followed regularly, and no suspicious alteration was found on imaging during the follow-up period.

After VAE, 59 patients without open excision underwent regular follow-up. Five (8.5\%) of the 59 patients presented with hypoechoic lesions in the primary site (5-11 $\mathrm{mm})$ during the follow-up period, and 2 patients underwent VAE again. The histopathologic diagnoses were IDP and adenosis, respectively. Four patients (6.8\%) had new nodules less than $5 \mathrm{~mm}$ in diameter but not in primary sites, and the US categories were $\mathrm{C} 2$ and $\mathrm{C} 3$. These four patients did not undergo VAE, and no enlargement process was revealed in the follow-up. In 5 patients with multifocal lesions, nodules less than $5 \mathrm{~mm}$ in diameter were not excised in the initial VAE. Three patients presented no nodules, and no alterations were found in the nodules of the other 2 patients during the follow-up period (Table 4).

Table 4 The follow-up results of patients underwent no open surgery $(n=59)$

\begin{tabular}{ll}
\hline Results & No. (\%) \\
\hline New nodules in primary site & $5(8.5)$ \\
Re-operation & $2(40)$ \\
New nodules not in primary site & $4(6.8)$ \\
Multifocal nodules not excised & $5(8.5)$ \\
No alteration & 2 \\
No nodule & 3 \\
\hline
\end{tabular}




\section{Discussion}

Papillary lesions are a heterogeneous group of breast lesions that include benign papillomas, atypical papillomas, and papillary carcinomas. Intraductal papilloma usually presents with nipple discharge or a palpable mass, and surgical management is the common procedure. However, an increasing number of papillomas are occasionally detected by image screening in the preclinical stage, which usually presents with no clinical symptoms. Some of these lesions are seen sonographically as solid nodules that are not distinguishable from other solid lesions in the breast. It has been suggested that these preclinical papillary lesions require additional surgical excision because they tend to cancerate [8]. In the present study, we found that $56.5 \%$ of patients with papilloma were asymptomatic, and $54.2 \%$ were categorized as BI-RADS 4a on ultrasonographic images. Only $32.3 \%$ of intraductal lesions were identified on an ultrasonographic check-up. However, patients with nipple discharge were more easily identified with ultrasonography (63.6\%), possibly because the papilloma was visible in the dilated duct, which was full of fluids. The average papilloma size was $12 \mathrm{~mm}(5-30 \mathrm{~mm})$ in our study, so it was difficult to differentiate small, impalpable papillary lesions. It was especially difficult to excise lesions with such a small size, but CNB guided by ultrasound was the applicable method to diagnose these lesions. However, because of insufficient tissue collected at biopsy, it was sometimes difficult to distinguish malignant from benign papillary lesions using CNB [9].

Some studies have recommended that papillary lesions diagnosed by CNB, especially those with atypia, should be subjected to open surgery for an accurate diagnosis because the rate of upgrading to malignancy is high in such situations [10, 11]. Regarding benign IDP without atypia, previous studies have reported that the rates of upgrading vary widely following excision. Some studies have shown that IDPs are significantly associated with higher-grade lesions, and open excision is recommended in all cases [10, 12]. However, other reports have suggested clinical and imaging follow-up rather than surgical excision because the rate of upgrading is low in IDP without atypia $[13,14]$. Therefore, the management of benign IDPs diagnosed by CNB remains controversial. Several studies have shown that the upgrading rate after open excision is associated with the adequacy of samples in biopsy lesions, even though the needle gauge used in CNB plays an important role in upgrading the rate of IDP $[15,16]$. In our study, we found an underestimation of $2 / 26(7.7 \%)$ following open excision after VAE. IDP with AHP was diagnosed in one patient initially diagnosed with IDP on VAE, and the other was diagnosed with intraductal papillary carcinoma after an initial diagnosis of IDP with sclerosing adenosis on VAE. Our underestimation rate was lower than those of other authors. For example, Tatarian et al. found that $21.3 \%$ of patients who were initially diagnosed with benign papilloma with CNB had IDP with atypia following surgical excision, and the majority of the atypical lesions were obtained from the tissue surrounding the papilloma [17]. The reason for the low rate of underestimation in our patients may be the sufficient samples (mean 8 tissue cores) obtained with VAE (8 gauge needle). Cassano et al. [18] also believed that further verification with open excision was not necessary in patients diagnosed with benign lesions by VAE. They showed that patients diagnosed with IDP with VAE exhibited no recurrence or progression when followed up for several months via imaging check-ups [18]. Obviously, the several-month follow-up was too short in the above study; however, a follow-up was conducted for 38 months in our patients who underwent VAE, and suspicious alterations were not found on images, which means VAE is an applicable method of diagnosing and treating breast papillary lesions. However, of the two downregulated patients, one was diagnosed with intraductal papillary cancer after open surgery. This patient suffered simultaneously from contralateral invasive ductal cancer, and her initial diagnosis was IDP with sclerosing adenosis on VAE. Consequently, attention should be paid to such patients when VAE is applied.

In the present study, we found that the average lesion diameter in IDPs with AHP $(21 \mathrm{~mm})$ was greater than that in IDPs $(13 \mathrm{~mm})$, which means that AHP was associated with lesion size. It has been reported that the BIRADS category is associated with upgrade rates in benign IDP diagnosed by CNB [19]. In our study, 10 patients with BI-RADS category $4 \mathrm{~b}$ and $4 \mathrm{c}$ on US images underwent open surgery. The histopathological examinations were IDPs in 6 patients and IDP with APH in 4 patients. We could not find the relation between the upgrading rate and BI-RADS category, which might be because of fewer upgrading cases. However, we found that $54.2 \%$ of papillary lesions were categorized as BIRADS $4 a$ on images, and the $C 3$, and $C 4 b, C 4 c$ category only accounted for $11.7 \%$ (10 cases) of the total patients. Therefore, papillary lesions must be kept in mind when breast lesions are categorized as $4 \mathrm{a}$ on ultrasonographic images.

Several reports have revealed that in more than $95 \%$ of patients, ultrasound-guided VAE can entirely remove papillomas that measure less than $15 \mathrm{~mm}$ and therefore has therapeutic value to avoid open surgery [7, 20]. In our patients, the largest diameter of the lesion was 30 $\mathrm{mm}$, and we completely excised the lesions via VAE guided by ultrasonography. In the follow-up period, $8.5 \%$ $(5 / 59)$ of patients presented with hypoechoic lesions in the primary site on ultrasonogram, 2 patients underwent 
VAE again, and the histopathological diagnoses were IDP and adenosis. The other 3 patients were followed up, and no suspicious alterations were found on images. Because only two patients underwent VAE again, the recurrence rate could not be determined. We might not have entirely removed all lesions with VAE in these patients because the lesion sizes were larger than the needle groove, and tiny residual lesions could not be detected with ultrasonography. There were 5 cases of multifocal lesions on the initial ultrasonogram in our study, and lesions less than $5 \mathrm{~mm}$ in diameter were not excised. After an average follow-up of 38 months, we found that 3 in 5 patients presented no lesions, and no enlargement process was found in the other 2 patients' lesions. Donaldson et al. [21] found that the 7-year cumulative breast cancer incidence rate was only $10 \%$ in patients who had an initial diagnosis of AHP on CNB, so they believed that close imaging follow-up was applicable to these patients. Furthermore, breast papillary carcinoma is rare, representing only $1-2 \%$ of all breast malignancies [22]. Therefore, we consider that it is not necessary to excise lesions less than $5 \mathrm{~mm}$ in diameter, especially in patients with multifocal papillomas.

\section{Conclusions}

VAE was applicable for completely excising papillomas, even IDPs with AHP, for an accurate diagnosis because of sufficient samples for pathological examination. In addition to the lower underestimation rate, the recurrence rate was also very low in IDP diagnosed via VAE, so VAE was applicable for excising completely small lesions. Because of the short period of follow-up (approximately 3 years), the canceration rate of papilloma after VAE deserves further study.

\section{Abbreviations}

CNB: Core needle biopsy; VAE: Vacuum-assisted excision; IDP: Intraductal papilloma; AHP: Atypical hyperplasia; BI-RADS: Breast image-report and data system

\section{Acknowledgements}

Not applicable.

\section{Authors' contributions}

$X H L$ and $H G$ drafted the work; $M L X$ and $Y W$ interpreted and analysed the data; DZ G designed the work and revised it. All authors have read and approved the manuscript, and ensure that this is the case.

\section{Funding}

The study was supported by the Research and Development Project of Digital Diagnosis and Treatment Equipment from the Ministry of Science and Technology of China. 2018YFC0114705 As a non-profit public institution, the funder subsidizes basic medical and clinical research nation widely.

\section{Availability of data and materials}

The datasets used and/or analysed during the current study are available from the corresponding author on reasonable request.

Ethics approval and consent to participate Not applicable.
Consent for publication

Not applicable.

\section{Competing interests}

The authors declare that they have no competing interests.

\section{Author details}

${ }^{1}$ Nosocomial Infection Department, The Second Hospital, Shandong University Cheeloo College of Medicine, Jinan 250033, China. ${ }^{2}$ Department of Thoracic and General Surgery, Shandong Provincial Chest Hospital, Jinan 250101, China. ${ }^{3}$ Maternity and Child Care Center of DeZhou, DeZhou 253015, China. ${ }^{4}$ Department of Breast Surgery, The Second Hospital, Shandong University Cheeloo College of Medicine, No. 247, Beiyuandajie Street, Jinan 250033, China.

Received: 4 July 2020 Accepted: 8 September 2020

Published online: 15 September 2020

\section{References}

1. Carder PJ, Garvican J, Haigh I, Liston JC. Needle core biopsy can reliably distinguish between benign and malignant papillary lesions of the breast. Histopathology. 2005;46:320-7.

2. McGhan LJ, Pockaj BA, Wasif N, Giurescu ME, McCullough AE, Gray RJ. Atypical ductal hyperplasia on core biopsy: an automatic trigger for excisional biopsy? Ann Surg Oncol. 2012;19:3264-9.

3. Rizzo M, Lund MJ, Oprea G, Schniederjan M, Wood WC, Mosunjac M. Surgical follow-up and clinical presentation of 142 breast papillary lesions diagnosed by ultrasound-guided core-needle biopsy. Ann Surg Oncol. 2008; 15:1040-7.

4. Jakate K, De Brot M, Goldberg F, Muradali D, O'Malley FP, Mulligan AM. Papillary lesions of the breast: impact of breast pathology subspecialization on core biopsy and excision diagnoses. Am J Surg Pathol. 2012;36:544-51.

5. Nakano S, Sakamoto H, Ohtsuka M, Mibu A, Sakata H, Yamamoto M. Evaluation and indications of ultrasound-guided vacuum-assisted core needle breast biopsy. Breast Cancer. 2007;14(3):292-6.

6. Han SH, Kim M, Chung YR, Yun B, Jang M, Kim SM, Kang E, Kim EK, Park SY. Benign intraductal papilloma without atypia on core needle biopsy has a low rate of upgrading to malignancy after excision. J Breast Cancer. 2018; 21(1):80-6.

7. Kibil W, Hodorowicz-Zaniewska D, Szczepanik A, Kulig J. Ultrasound-guided vacuum- assisted core biopsy in the diagnosis and treatment of focal lesions of the breast-own experience. Wideochir Inne Tech Maloinwazyjne. 2013;8(1):63-8.

8. Kil WH, Cho EY, Kim JH, Nam SJ, Yang JH. Is surgical excision necessary in benign papillary lesions initially diagnosed at core biopsy? Breast. 2008;17: 258-62.

9. Holley SO, Appleton CM, Farria DM, Reichert VC, Warrick J, Allred DC, Monsees BS. Pathologic outcomes of nonmalignant papillary breast lesions diagnosed at imaging-guided core needle biopsy. Radiology. 2012;265:37984.

10. Shiino S, Tsuda H, Yoshida M, Jimbo K, Asaga S, Hojo T, Kinoshita T. Intraductal papillomas on core biopsy can be upgraded to malignancy on subsequent excisional biopsy regardless of the presence of atypical features. Pathol Int. 2015;65:293-300.

11. Tokiniwa H, Horiguchi J, Takata D, Kikuchi M, Rokutanda N, Nagaoka R, Sato A, Odawara H, Tozuka K, Oyama T, Takeyoshi I. Papillary lesions of the breast diagnosed using core needle biopsies. Exp Ther Med. 2011;2(6):1069-72.

12. Nakhlis F, Ahmadiyeh $N$, Lester $S$, Raza S, Lotfi P, Golshan M. Papilloma on core biopsy: excision vs. observation. Ann Surg Oncol. 2015;22:1479-82.

13. Pareja F, Corben AD, Brennan SB, Murray MP, Bowser ZL, Kiran SJ, Morrow C, Morris M, Brogi E. Breast intraductal papillomas without atypia in radiologicpathologic concordant core-needle biopsies: rate of upgrade to carcinoma at excision. Cancer. 2016;122:2819-27.

14. Ko D, Kang E, Park SY, Kim SM, Jang M, Yun B, Chae S, Jang Y, Kim HJ, Kim SW, Kim EK. The management strategy of benign solitary intraductal papilloma on breast core biopsy. Clin Breast Cancer. 2017;17:367-72.

15. Youk JH, Kim EK, Kwak JY, Son EJ, Park BW, Kim SI. Benign papilloma without atypia diagnosed at US-guided 14-gauge core-needle biopsy: clinical and US features predictive of upgrade to malignancy. Radiology. 2011;258(1):81-8. 
16. Seely JM, Verma R, Kielar A, Smyth KR, Hack K, Taljaard M, Gravel D, Ellison E. Benign papillomas of the breast diagnosed on large-gauge vacuum biopsy compared with 14 gauge core needle biopsy- do they require surgical excision? Breast J. 2017:23(2):146-53.

17. Tatarian T, Sokas C, Rufail M, Lazar M, Malhotra S, Palazzo JP, Hsu E, Tsangaris T, Berger AC. Intraductal papilloma with benign pathology on breast core biopsy: to excise or not? Ann Surg Oncol. 2016;23:2501-7.

18. Cassano E, Urban LA, Pizzamiglio M, Abbate F, Maisonneuve P, Renne G, Viale G, Bellomi M. Ultrasound-guided vacuum-assisted core breast biopsy: experience with 406 cases. Breast Cancer Res Treat. 2007;102:103-10.

19. Shin HJ, Kim HH, Kim SM, Yang HR, Sohn JH, Kwon GY, Gong G. Papillary lesions of the breast diagnosed at percutaneous sonographically guided biopsy: comparison of sonographic features and biopsy methods. AJR Am J Roentgenol. 2008;190:630-6.

20. Plantade R, Hammou JC, Gerard F, Chanalet I, Aubanel D, David-Bureau M, Scotto A, Fighiera M, Gueret S, Lo Monaco L. Ultrasound-guided vacuumassisted biopsy: review of 382 cases. J Radiol. 2005;86:1003-15.

21. Donaldson AR, McCarthy C, Goraya S, Pederson HJ, Sturgis CD, Grobmyer SR, Calhoun BC. Breast cancer risk associated with atypical hyperplasia and lobular carcinoma in situ initially diagnosed on core-needle biopsy. Cancer. 2018;124:459-65.

22. Ali-Fehmi R, Carolin K, Wallis T, Visscher DW. Clinicopathologic analysis of breast lesions associated with multiple papillomas. Hum Pathol. 2003;34: 234-9.

\section{Publisher's Note}

Springer Nature remains neutral with regard to jurisdictional claims in published maps and institutional affiliations.

Ready to submit your research? Choose BMC and benefit from:

- fast, convenient online submission

- thorough peer review by experienced researchers in your field

- rapid publication on acceptance

- support for research data, including large and complex data types

- gold Open Access which fosters wider collaboration and increased citations

- maximum visibility for your research: over $100 \mathrm{M}$ website views per year

At $\mathrm{BMC}$, research is always in progress.

Learn more biomedcentral.com/submissions 